\title{
Nano-Intermetallic Precipitated Al-Based Amorphous Matrix Composite Design by Artificial Neural Network Analysis
}

\author{
S. Ganguly ${ }^{1,2}$, O. A. Ojo ${ }^{1}$, P. P. Chattopadhyay ${ }^{3} \&$ D. Roy ${ }^{1,4}$ \\ ${ }^{1}$ Mechanical and Manufacturing Engineering Department, University of Manitoba, Winnipeg, Canada \\ ${ }^{2}$ School of Materials Science and Engineering, Bengal Engineering and Science, University, Shibpur, Shibpur, \\ Howrah, India \\ ${ }^{3}$ Department of Metallurgy \& Materials Engineering, Bengal Engineering \& Science, University, Shibpur, \\ Howrah, India \\ ${ }^{4}$ Materials and Metallurgical Engineering Department, NIFFT, Ranchi, India \\ Correspondence: D. Roy, Mechanical and Manufacturing Engineering Department, University of Manitoba, \\ Winnipeg, Canada, R3T 5V6. Tel: 91-651-229-1125. E-mail: droy2k3@yahoo.co.in
}

Received: March 1, 2012 Accepted: March 20, 2012 Online Published: June 10, 2012

doi:10.5539/jmsr.v1n3p59 URL: http://dx.doi.org/10.5539/jmsr.v1n3p59

\begin{abstract}
The present study concerns development of suitable model to understand the influence of microstructure on the mechanical properties of $\mathrm{Al}_{65} \mathrm{Cu}_{20} \mathrm{Ti}_{15}$ nano intermetallic dispersed amorphous matrix composite using the artificial neural network (ANN).). Model behavior has been evaluated to predict the role of different consolidation parameters such as temperature, pressure, and time on the mechanical properties of the alloy. A set of processing parameters were evolved through the analysis of the models which were used to develop the consolidated bulk alloy under appropriate experimental schedule. The microstructure and mechanical properties of the bulk alloy have been investigated to understand the structure property and high pressure sintering process (HPS) correlation. Artificial Neural Network model exposed that the temperature of $350-450{ }^{\circ} \mathrm{C}$ and the pressure of about 2-4 GPa are most suitable sintering parameters for obtaining favorable mechanical properties of the alloy.
\end{abstract}

Keywords: nano-material, sintering, mechanical properties, neural network

\section{Introduction}

In recent years, Al-rich amorphous alloys have drawn a special attention as potential structural materials with exceptionally high specific strength. In such alloys the achievable strength is much higher than that of the high strength age-hardenable Al-alloys (Inoue, 2000; Kiminami, Basim, Kaufman, Amateau, Eden, \& Galbraith, 2001; Masumoto, 1994). Amorphous alloys derive their strength directly from their non-crystalline structure, which does not have any of the defects (such as dislocations) that limit the strength of crystalline age- hardenable alloys The non-equilibrium processes like mechanical alloying and rapid solidification have been successfully employed to meet the challenge of achieving the amorphous/glassy-state in Al-alloys (Suryanarayana, 2001; Fecht, 1992; Liu, Dong, Li, Yu, \& Zou, 2005). It has also been reported that dispersion of nanocrystalline phases in amorphous matrix further improve the strength and toughness (Manaila, Macovei, Popescu, Devenyi, Jianu, \& Vasile, 2000; Li, Zhao, \& Jiang, 2003; Peker \& Johnson, 1993) of the alloys.

Several amorphous and nano-intermetallic dispersed amorphous microstructures have been developed by mechanical alloying having the nominal composition of $\mathrm{Al}_{65} \mathrm{Cu}_{\mathrm{x}}(\mathrm{Ti}, \mathrm{Nb}, \mathrm{Zr})_{35-\mathrm{x}}$ (Manna, Nandi, Bandyopadhyay, \& Ghoshray, 2004b; Manna, Nandi, \& Nambissan, 2004c; Manna, Chattopadhyay, Banhart, \& Fecht, 2004a; Chattopadhyay, Gannabattula, Pabi, \& Manna, 2001). Different consolidation techniques including hot/warm pressing and extrusion methods are used to consolidate the ball milled product into bulk samples (Zhao \& Jiang, 2003; Kawamura, Mano, \& Inoue, 2001; Schurack, Eckert, \& Schultz, 2000; Nygren \& Shen, 2003). Selection of temperature and pressure in consolidation of the mechanically alloyed amorphous/nanocrystalline powders is most crucial to achieve most preferred mechanical properties. In this context, reasonable amount of experimented data has already been generated through numbers of recent investigations (Roy, Kumari, Mitra, \& Manna, 2007; Roy, Chudoba, Witczak, Lojkowski, Fecht, Mitra, \& Manna, 2008; Roy, 2008). Therefore, it may 
be of interest to employ data driven model to predict and understand the general correlation between sintering parameters and mechanical property. Among the data driven modeling techniques, artificial neural network is gaining increasing interest to solve problems of mapping one or more responses related in complex manner to a high dimensional input variables space (Bhadeshia, 1999; Aijun, Hejun, Kezhi, \& Zheng, 2004; Lin, Zhang, \& Zhong, 2008; Datta, Pettersson, Ganguly, Saxén, \& Chakraborti, 2007; Brady \& Tortorelli, 2004; Maa, Zhu, Wuab, \& Zhang, 2009, McBride, Malinov, \& Sha, 2004; Jang, Sun, \& Mizutani, 1997).

The present work is aimed at development of a prediction model to correlate the sintering variables and mechanical properties of the $\mathrm{Al}_{65} \mathrm{Cu}_{20} \mathrm{Ti}_{15}$ alloy by artificial neural network (ANN) technique using the available data reported in the literature. The model has been appropriately evaluated to predict the most suitable sintering parameters so as to achieve superior mechanical properties of the alloy consolidated in high pressure sintering route. Attempt has also been made to consolidate the alloy powder using the sintering parameters chosen through the analysis of the model predictions. Microstructural and mechanical properties of the samples have been examined to validate the model responses.

\section{Neural Network Modeling}

The basic element of an artificial neural network is called a neuron and these neurons are linked to each other with weight factor known as synaptic connections weight. In perceptron model, connection weights are adjusted during the training procedure. This process is continued until a good performance measure is reached against the dynamic set of the weights and the networks are trained against reasonable numbers of input-output pairs. Among the varieties of neural networks, multi layer perceptron kind of neural network are widely used in developing prediction models.

\subsection{Network Design}

The general structure of the neural network is schematically shown in Figure 1. The input and output layers are connected by the hidden layers. Due to the flexible nature of tan sigmoid transfer function a single hidden layer between input and out layer, with appropriate number of neuron, can capture any degree of nonlinearity in the relationship (Martin, 1992). Therefore, in this exercise an input layer-single hidden layer-output layer network, with a tan-sigmoid transfer function in the input to hidden layer and a linear transfer function in the hidden layer to output layer, is implemented. The number of neurons in the output layer is predetermined by the number of outputs to train, which is 1 in this case, the hardness or compressive strength of the alloy under study. The choice of number of neurons in the input to hidden layer is bottle neck of the problem. The common approach is to find optimum number of neurons in the hidden layers through exhaustive trials. However, a typical guess has been made for the starting point considering number of input to output ratio and the nonlinearity factor of the problem (Basheer \& Hajmeer, 2000). On the other hand the maximum number of neurons in the hidden nodes is restricted by the number of the data pairs available for training. For a statically significant training the number of connections parameters (weights and biases) to be fitted is kept smaller than the number of the data pairs available in the training set (Sha \& Edwards, 2007). Trials are made by repeating the similar operations for varying number of hidden units of the hidden layers in order to search the optimal network using a Matlab routine. The exhaustive trials conducted herein, revealed that network architecture with 10 and 8 neurons in the hidden layers are optimum for hardness and compressive strength model. Generalize mathematical description of such network architecture is described bellow.

The inputs $\left(x_{i}\right)$ are multiplied by weights $\left(w_{i j}\right)$ for a hidden node $\left(h_{j}\right)$; summation of all the $\mathrm{w}_{\mathrm{ji}} \mathrm{x}_{\mathrm{i}}$ is then added to a bias value $\left(b_{j}\right)$ and finally operated by a suitable transfer function $(f)$, tan sigmoid in this case. The operation can be written as:

$$
h_{j}=f\left(\sum w_{i j} x_{i}+b_{j}\right)
$$

In the course of calculation, as stated earlier, the hidden layer contributes to the output neuron through a linear operation to yield the final network output, (y), i.e., hardness or compressive strength of the alloy in this work, as follows:

$$
y=\left(\sum w_{k} h_{k}+b^{\prime}\right)
$$

where $\mathrm{w}_{\mathrm{k}}$ and $\mathrm{b}^{\prime}$ are new sets of weights and bias values for the hidden layer to output neuron During the training process, the deference between the instantaneous output value predicted by the model and the target value of the network response is back propagated to adjust the whole set of weights and biases to obtained a finally trained 
network.

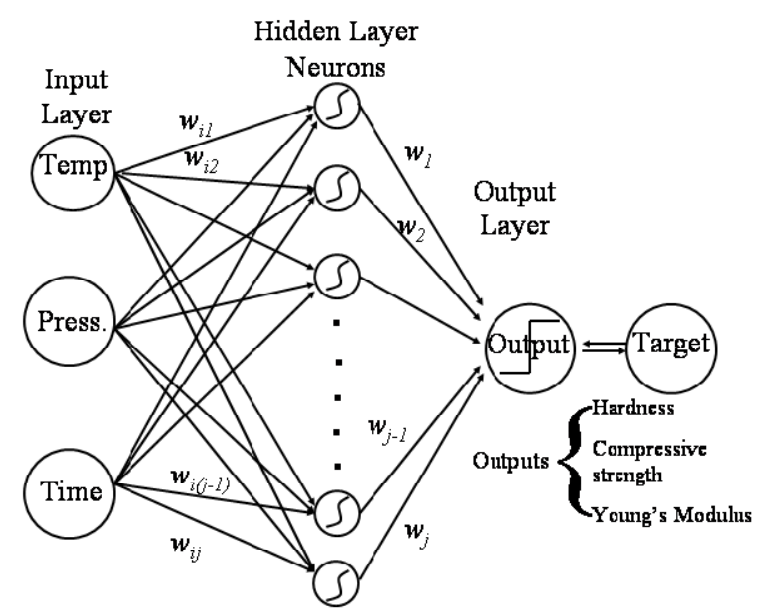

Figure 1. Schematic illustration of general structure of the neural network model
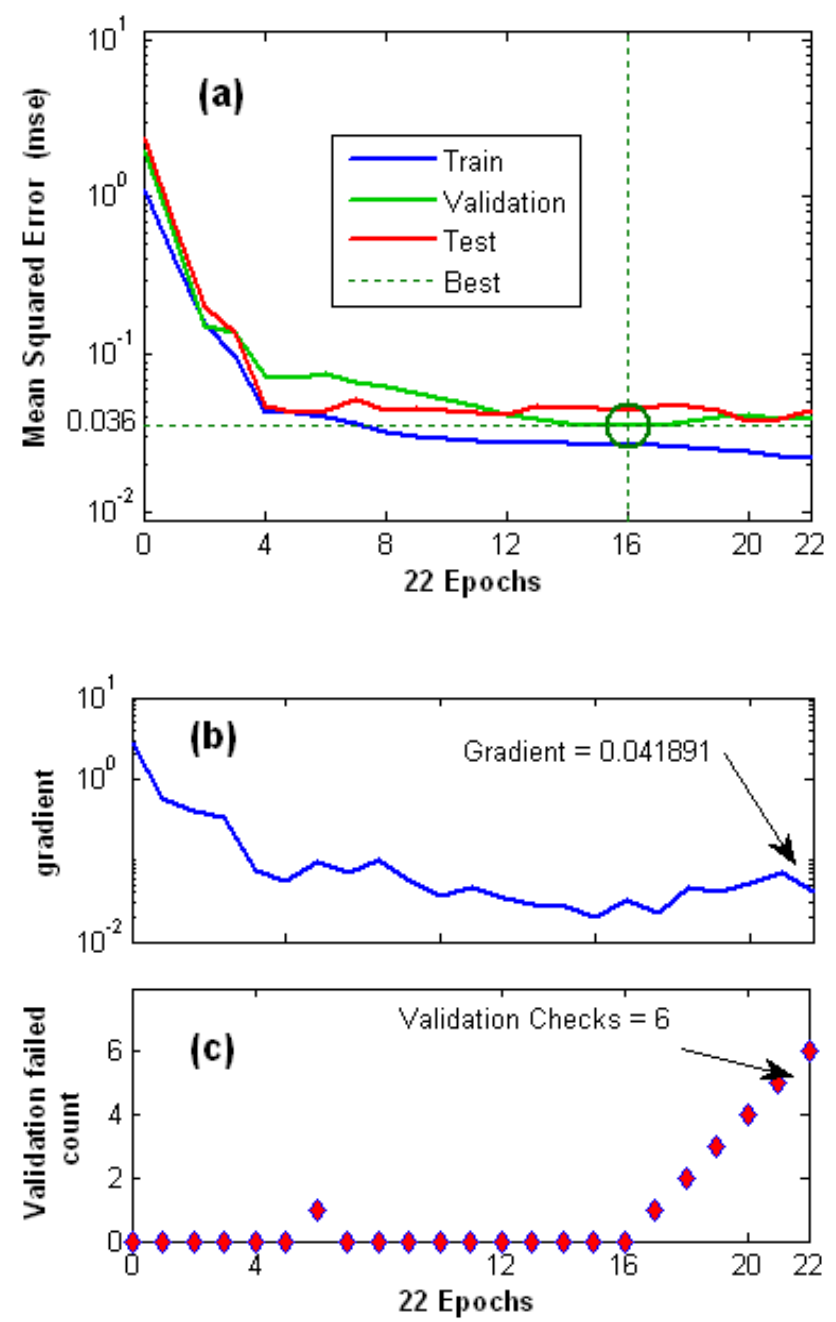

Figure 2. Typical changes noticed during advancement of training procedure of hardness model in (a) mean square error (b) gradient of training error curve and (c) count of data failed in validation check against the training iteration 


\subsection{Network Training and Testing}

The data set used for training the present network is summarized in Table 1. The input and output pairs for the consolidation processes of the alloy were collected from the published literatures (Roy, Kumari, Mitra, Manna, 2007; Roy, Chudoba, Witczak, Lojkowski, Fecht, Mitra, Manna, 2008; Roy, 2008). To improve the efficacy of network training, the whole data set were scaled to -1 to +1 using equation 3 and a counter operation was performed to revert back the network output in real scale.

$$
X_{N}=\frac{2 \times\left(x-x_{\min }\right)}{\left(x_{\max }-x_{\min }\right)}-1
$$

where $x_{N}$ is the transformed value of a variable $x$, and $x_{\max }$ and $x_{\min }$ are the maximum and minimum values of $x$ respectively.

Table 1. Statistical description of the data set used for ANN training

\begin{tabular}{cccccc}
\hline Parameters & Units & Minimum & Maximum & Mean & Standard Deviation \\
\hline Sintering temperature & ${ }^{0} \mathrm{C}$ & 300 & 600 & 465 & 100.7 \\
Sintering pressure & $G P a$ & 0.05 & 8.0 & 2.4 & 3.12 \\
Sintering time & Minute & 1 & 20 & 9.35 & 6.2 \\
Hardness & $G P a$ & 1.37 & 20 & 7.88 & 3.01 \\
Compressive strength & $M P a$ & 46 & 2037 & 1155 & 568 \\
\hline
\end{tabular}

As discussed earlier section supervised single hidden layered feed forward network with gradient descent back propagation algorithms have been adopted to train the hardness and compressive strength separately in this problem. Consolidation temperature, pressure and time are considered as the model inputs variables of the system. The hyperbolic tangent (tanh) and scale conjugate gradient algorithms were implemented as transfer function and training rule respectively, for the training procedure. One such training plot along with the gradient information of the training error curve and number of cases failed in validation against the training iteration is shown in Figure 2. Since the set of error curves shows similar characteristics for a significant number iterations which means the overfitting is carefully avoided and the training is reasonable good.

\section{Experimental Procedures}

For experimental verification of the proposed models a suitable scheme was developed for prepareing the samples. The powder blends comprising elemental $\mathrm{Al}, \mathrm{Cu}$ and $\mathrm{Ti}$ in appropriate proportion were prepared with the nominal stoichiometry of $\mathrm{Al}_{65} \mathrm{Cu}_{20} \mathrm{Ti}_{15}$. The powder were subjected to mechanical alloying in a Retsch PM 400 high-energy planetary ball mill operated at $300 \mathrm{rpm}$ with 10:1 ball to powder weight ratio using tungsten carbide (WC) coated vial and balls (10 mm diameter) (Suryanarayana, 2001). Ball milling was carried out in wet (toluene) medium to prevent the agglomeration of powders and to retard the oxidation (Suryanarayana, 2001). The alloy powder milled for 25 hours was first cold-compacted at a uniaxial pressure of $100 \mathrm{MPa}$ in vacuum $\left(4 \times 10^{-8} \mathrm{MPa}\right)$ using a manual press. These cold pressed cylindrical preforms of $5 \mathrm{~mm}$ diameter and $5-6 \mathrm{~mm}$ height were mounted in ceramic containers, and positioned between tungsten carbide anvils, where heating was carried out using graphite susceptor coils. The samples were sintered at different temperatures $\left(300-600{ }^{\circ} \mathrm{C}\right)$ under a uniaxial pressure of $8 \mathrm{GPa}$ for $1 \mathrm{~min}$.

During sintering of the mechanically alloyed product, critical parameters were precisely determined by analysis of the results obtained from the ANN model. The compaction of the powder sample was confirmed by verifying the density using standard density measurement technique (Gregg \& Sing, 1982). The consolidated samples were used for physical and mechanical properties to validate the model behavior.

The phase evolution in the sintered product were studied by X-ray diffraction (XRD, K $\alpha$ radiation, $\lambda=0.1542$ $\mathrm{nm}, 30 \mathrm{KV}, 15 \mathrm{~mA})$. The microstructure and composition of different phases in the composite samples were examined using a JEOL JEM 2100 high-resolution transmission electron microscope (HRTEM) at an acceleration voltage $20 \mathrm{kV}$. The specimen for HRTEM studies were prepared using mechanical polishing, 
followed by argon ion milling on a GATAN precision ion mill for 30 min. Hardness measurement was carried out using a nanoindentation tester (Nanoindentor-XP, NanoInstrument Inc, USA). An average of 20 reading was taken to represent the hardness value in each case.

Compression tests were carried out at room temperature at a strain rate of $1 \times 10^{-3} \mathrm{~s}^{-1}$ using a universal testing machine. Specimens with $3 \mathrm{~mm} \times 3 \mathrm{~mm}$ cross sectional area and $6 \mathrm{~mm}$ height were cut from sintered compacts and compressed between parallel plates coated with tungsten carbide. The load and displacement were measured by using a quartz load cell of $5 \mathrm{kN}$ capacity (accuracy $\pm 1 \mathrm{~N}$ ) and high accuracy digital strain gauge (accuracy \pm 1 $\mathrm{mm}$ ), respectively The apparatus for such measurement was presented elsewhere (Witczak, 1997). Average three sample reading was taken to represent the compressive strength value in each case.

\section{Results and Discussion}

The methodology was used to develop two differently trained neural networks for prediction of hardness and compressive strength. The whole data set was divided into three different parts in the ratio of 4:1:1 for training testing and validation of the models. The training and testing data set were used to develop the models while the validation set was used to check the prediction accuracy of the model. The network outputs are plotted versus the targets and illustrated in Figure 3 along with the relative error plots for training testing and validation data set of each of the properties. The regression correlation was computed to check the model accuracy on the data used to build the model (training and testing set) and the unknown data (validation set) as well. The correlation coefficient and the relative error plots clearly indicate that the performance level of both the models has been found satisfactory. It is evident that the prediction accuracy performances of the models show a reliable agreement with the target values. The scatters in the data points are apparently marginal. These models were used for simulation and analysis. Systematic simulations of these models were for further analysis of the system.
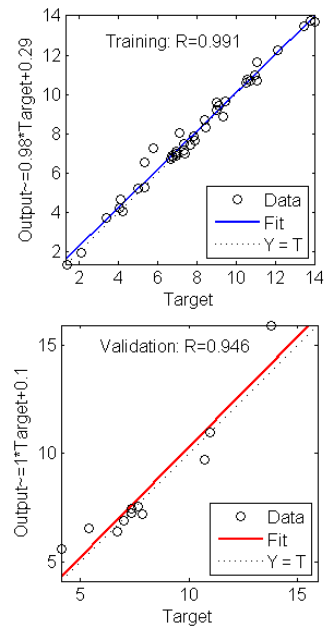
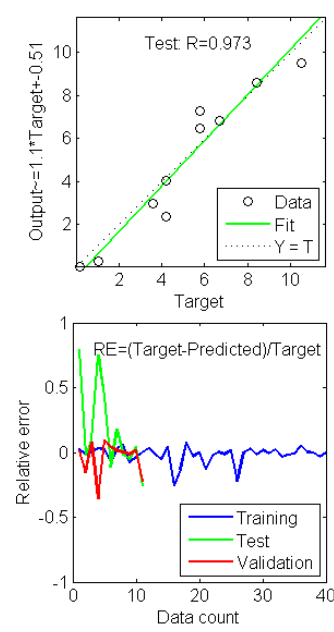
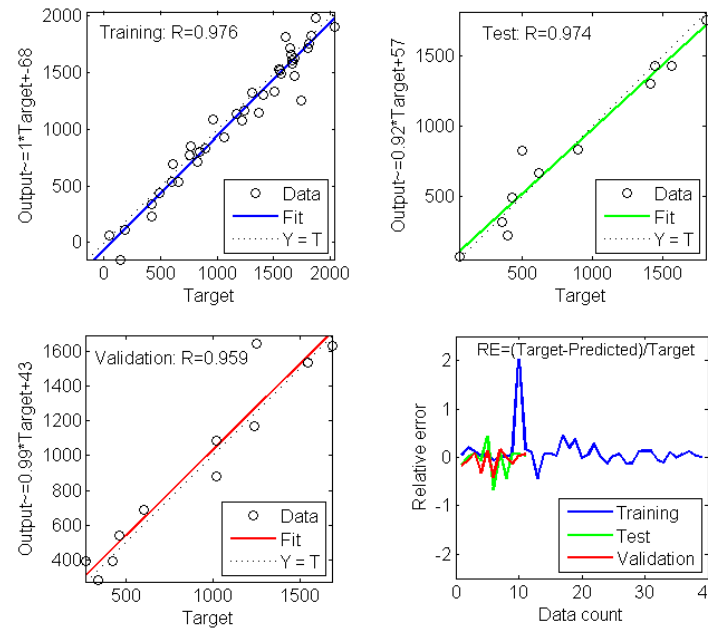

Figure 3. Illustrate the model prediction accuracy on the known (training and testing data) and unknown (validation data) with the help of network outputs plotted versus the target and the relative error plots for (a) hardness and (b) compressive strength of $\mathrm{Al}_{65} \mathrm{Cu}_{20} \mathrm{Ti}_{15}$ alloy

\subsection{Model Insight for Mechanical Properties of the Alloy}

Figure 4(a)-(c) depict the response surfaces showing variation of compressive strength against the sintering pressure and temperature at varying time duration. The observed variations in all the three cases are in general of similar nature. The plots clearly revealed that the compressive strength is higher in the regime of high temperature $\left(>450^{\circ} \mathrm{C}\right)$ and moderate pressure $(\sim 4 \mathrm{GPa})$. Earlier, the glass transition temperature for this alloy has been identified of about $400{ }^{\circ} \mathrm{C}$ (Roy, 2008). In this regard, it is known that diffusivity in the amorphous microstructure is much higher at the temperatures above glass transition temperature (Geyer, Johnson, Schneider, Qiu, Tombrell, \& Macht, 1996). Therefore, in the present alloy the strength obtained at higher sintering temperature may be attributed to the enhanced diffusion process which resulted into strong bonding among the aggregates/particles favoring the sintering process. However, high temperature in combination with high pressure resulted in marginal drop in the compressive strength. Earlier, studies have reported significant crystallization of the amorphous matrix under the combination of higher temperature and pressure which causes 
deterioration of strength. It is apparent from Figure 4(a) and (b) that at lower than glass transition temperatures, variation of compressive strength with pressure is similar up to a holding time of 10 minutes. However in case of 20 minutes holding time, the compressive strength sharply drops with increasing pressure at lower temperature (Figure 4(c)). Here, it is reasonable to conjecture that even at lower temperature prolong holding may form nanocrystalline intermetalilic phases resulting into decrease in compressive strength. An earlier study has shown that the presence of brittle intermetallic phases inhibits densification the powder blends (Senkov, Senkova, Scott, \& Miracle, 2005).
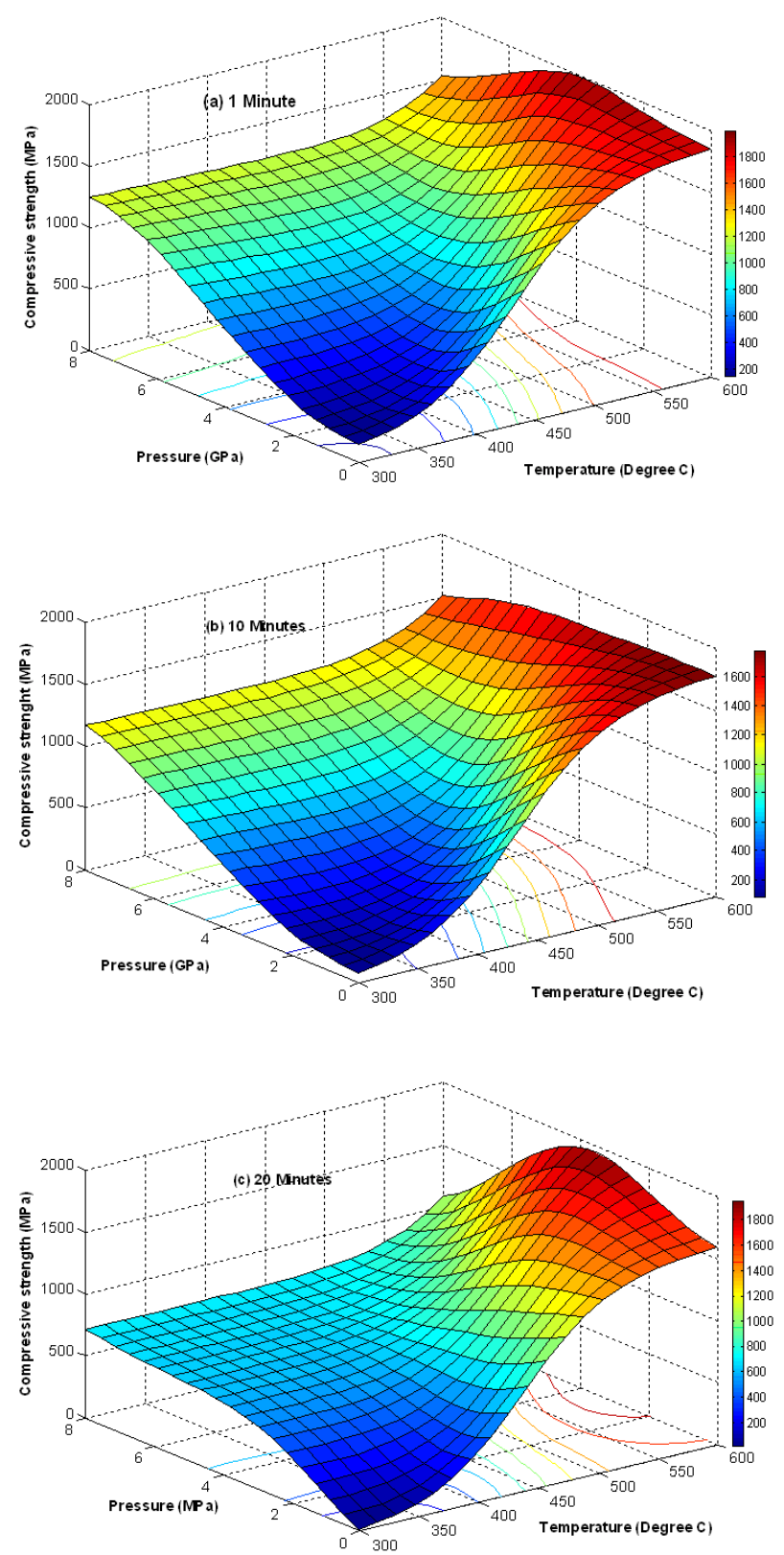

Figure 4. Model simulated response surfaces to study variations of HPS parameters on compressive strength at (a) 1, (b)10 and (c)20 minutes time

Figure 5 (a)-(c) show the response surfaces of variation of hardness as the function of pressure and temperature for different levels of duration. Comparison of the models shown in Figure 5 reveal that hardness increase with pressure at lower temperature, however, at higher temperature the same decreases from a peak value at lower pressure to the minimum value at higher pressure. It may be mentioned here that increase in temperature could lead to the formation of higher volume fraction of fine intermetallic phases. Presence of such ultra-fine 
intermetallic phases contributes significantly to the enhancement of hardness of the sintered product. The decrease in hardness at high pressure and at the high temperature may be attributed to the anomalous growth of intermetallic phases taking place on a larger scale. The presence of some larger grains, accounting for a significant volume fraction, could also contribute to a significant decrease in hardness.

\subsection{Experimental Verification of the ANN Results}

Analysis of the models reveals prominent variation of the properties at temperature of $350^{\circ} \mathrm{C}$ and $450^{\circ} \mathrm{C}$ at the pressure of about $2 \mathrm{GPa}$. In view of this, samples sintered at 350 and $450{ }^{\circ} \mathrm{C}$ were subjected to microsrructural and mechanical characterization with an aim to explore the mechanisms responsible for the observed variation.
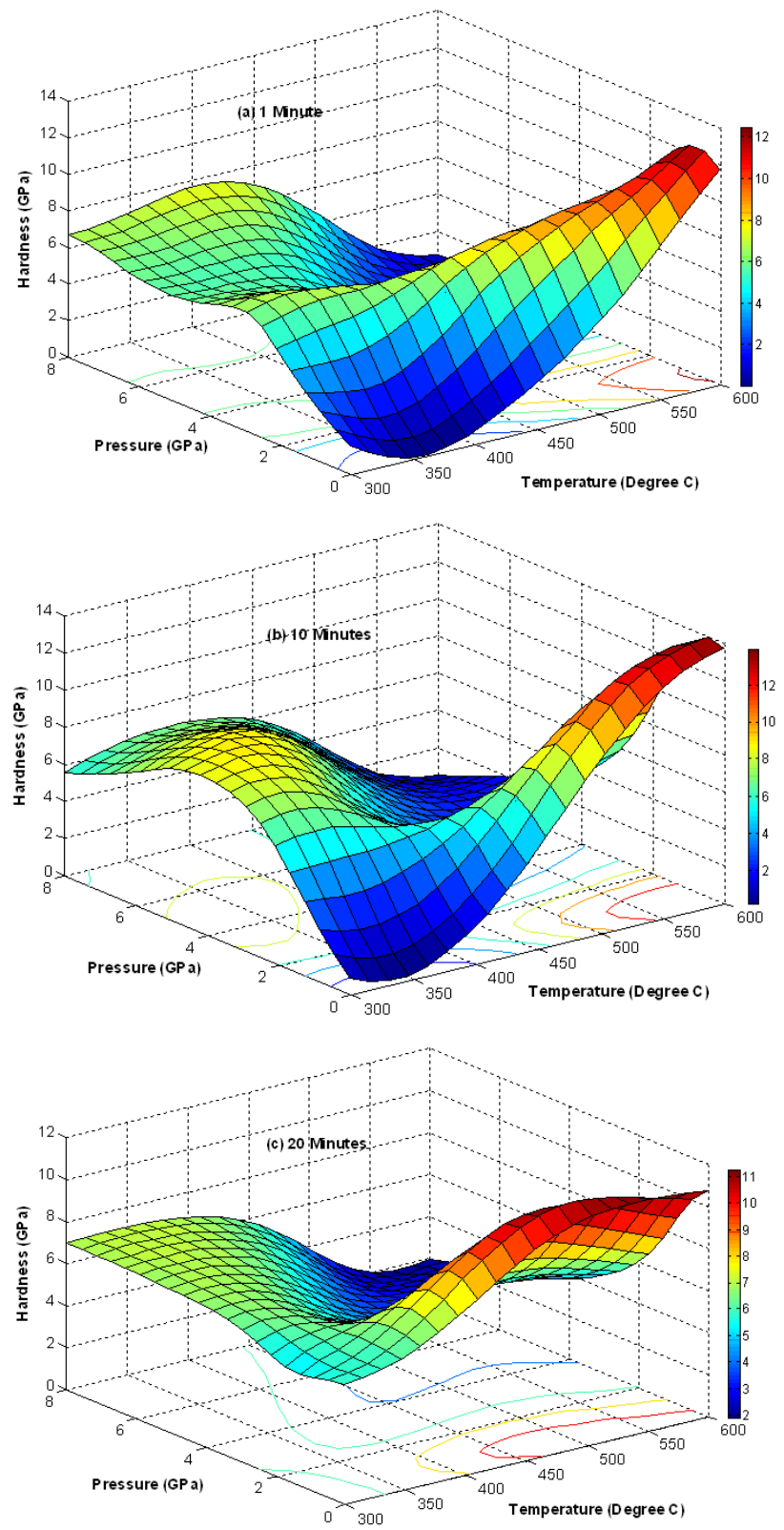

Figure 5. Model simulated response surfaces to study variations of HPS parameters on Hardness at (a)1, (b) 10 and (c)20 minutes time

\subsubsection{Mechanical Properties}

Figure 6 depicts the hardness, and compressive strength of the composites sintered at $350^{\circ} \mathrm{C}$ and $450^{\circ} \mathrm{C}$. It is interesting to record that the hardness is higher for sintering temperature of $350^{\circ} \mathrm{C}$, whereas compressive strength is higher for the sample that was sintered at $450^{\circ} \mathrm{C}$. Therefore, the experimental results of hardness do not corroborate the same results obtained from the ANN model. In this context, further scrutiny of the ANN results 
reveal that variation of hardness between the temperature ranges 350 to $450^{\circ} \mathrm{C}$ is only nominal, while the variation of compressive strength within the same temperature range is significant. It is apparent that the hardness value is dominantly determined by the mechanical behavior of the bulk grain. On the other hand, the compressive strength is more influenced by the nature of the interfaces. In view of this, it is reasonable to conjecture that in respect of hardness, the contribution of the amorphous aggregates at lower sintering temperature is more significant than the same of the partially crystalline matrix at higher temperature. However, lower value of compressive strength, at lower sintering temperature may be attributed to the weaker interfaces among the particles due to the difficulties in sintering of amorphous aggregates. Sintering at $450{ }^{\circ} \mathrm{C}$ allow better sintering due to favorable deformation condition in presence of the crystalline phases thereby resulting into higher value of compressive strength.

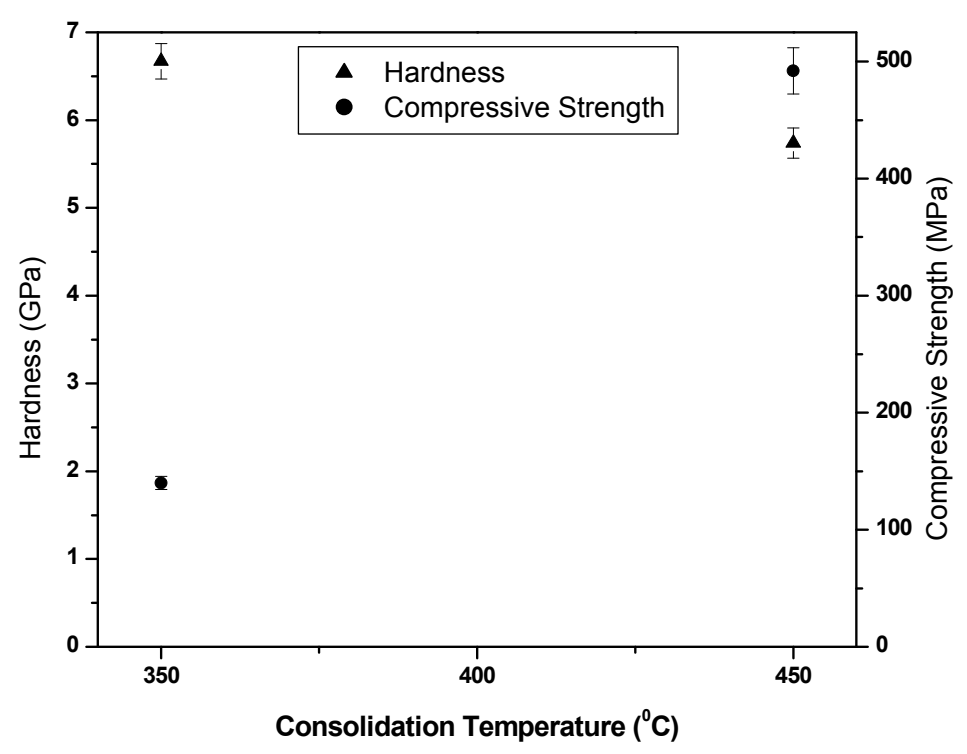

Figure 6. Experimentally observed mechanical properties of the alloy consolidated with 2 GPa pressure, 10 minutes time at two different temperatures $350{ }^{\circ} \mathrm{C}$ and $450{ }^{\circ} \mathrm{C}$

\subsubsection{Microstructure}

For better understanding of the mechanical responses of the high pressure sintered alloy, the samples were investigated through XRD and TEM study. Figure 7 shows the results of XRD analysis of the mechanical alloyed powders consolidated by high pressure sintering. The patterns suggest that sintering at $350^{\circ} \mathrm{C}$ produced bulk amorphous sample. Increase in sintering temperature to $450^{\circ} \mathrm{C}$ yielded perceptible crystallization of the as-milled amorphous aggregate and yields a metastable composite microstructure comprising several ultrafine intermetallic phases like $\mathrm{Al}_{5} \mathrm{CuTi}_{2}, \mathrm{Al}_{4} \mathrm{Cu}_{9}, \mathrm{Al}_{2} \mathrm{Cu}$ and $\mathrm{Al}_{3} \mathrm{Ti}$ in varying volume fraction dispersed in the amorphous matrix. The formation of these intermetallic phases is in conformance with the concerned ternary phase diagram (Roy, Kumari, Mitra, \& Manna, 2007).

Bright field TEM image and corresponding selected area diffraction (SAD) pattern obtained from the powder blends consolidated by HPS at $350^{\circ} \mathrm{C}$ and $450^{\circ} \mathrm{C}$ are shown in Figure 8 . Examination of the TEM images indicates that predominantly amorphous microstructure is achieved after consolidation at $350^{\circ} \mathrm{C}$ while nano crystalline of $\mathrm{Al}_{2} \mathrm{Cu}, \mathrm{Al}_{4} \mathrm{Cu}_{9}$ and $\mathrm{Al}_{5} \mathrm{CuTi}_{2}$ phases are dispersed in the Al-rich partially amorphous matrix after sintering at $450^{\circ} \mathrm{C}$. Therefore, the results obtained from the analysis of the TEM image and the corresponding $\mathrm{SAD}$ pattern corroborates the results of the XRD analysis shown in Figure 7. As observed, both of these characterizations of the alloy processed in the high pressure sintering condition judiciously explain the mechanical properties as well. 


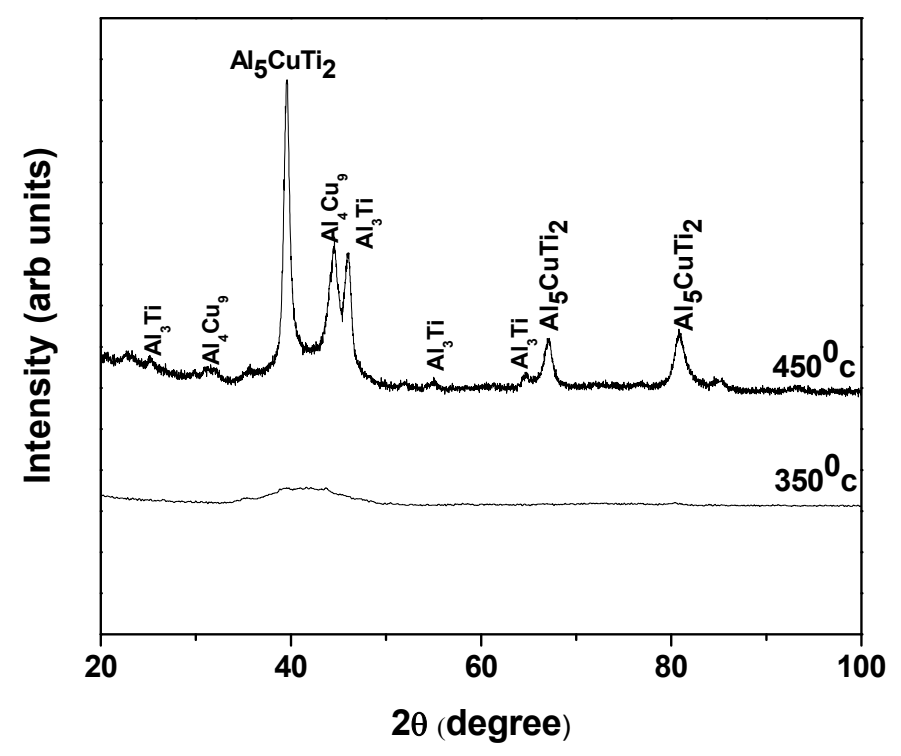

Figure 7. XRD patterns of the $\mathrm{Al}_{65} \mathrm{Cu}_{20} \mathrm{Ti}_{15}$ amorphous matrix composite consolidated by high pressure sintering at different temperatures
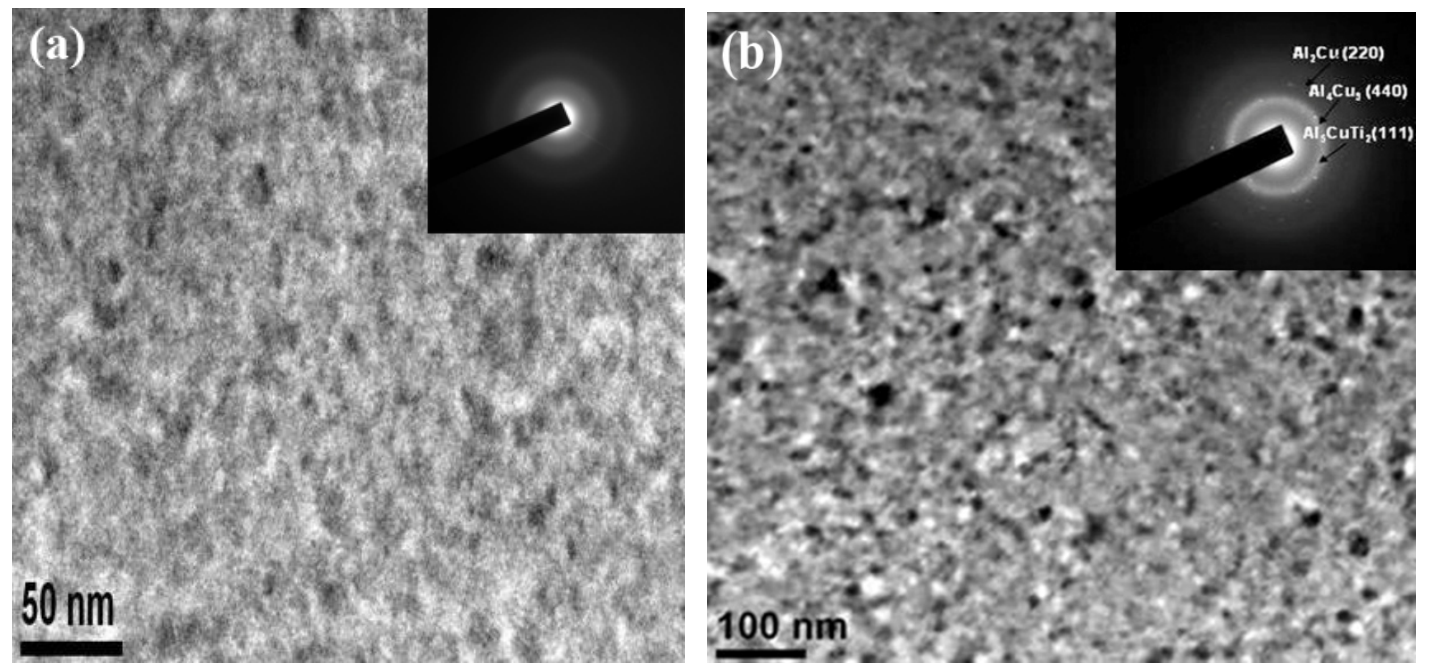

Figure 8. Bright field TEM image and corresponding selected area diffraction (SAD) pattern of Composite consolidated by high pressure sintering at (a) $350^{\circ} \mathrm{C}$ and (b) $450^{\circ} \mathrm{C}$

\section{Conclusion}

The major conclusions that emerged out of the present study are:

1) Artificial neural networks (ANN) have been successfully implemented to model the mechanical properties of bulk $\mathrm{Al}_{65} \mathrm{Cu}_{20} \mathrm{Ti}_{15}$ alloy synthesized by consolidation of ball milled powder blend.

2) Analysis of the results of the ANN model revealed that the temperature of $350-450{ }^{\circ} \mathrm{C}$ and the pressure of about 2-4 GPa are most suitable sintering parameters for obtaining favorable mechanical properties of the alloy.

3) The experimental results demonstrated that partially crystallized amorphous microstructure obtained at appropriate sintering temperature results into the best combination of compressive strength and hardness due to dominant contribution of amorphous phase on hardness of the aggregates and favorable role of the crystalline phases on sintering mechanism among the aggregates. 


\section{Acknowledgements}

The financial support for this study by NSERC of Canada is gratefully acknowledged. Authors are also thankful to Professor Indranil Manna, Director, Central Glass and Ceramic Research Institute Kolkata, India for his valuable assistance and discussion in connection to this research work.

\section{References}

Aijun, L., Hejun, L., Kezhi, L., \& Zhengbing, G. (2004). Applications of neural networks and genetic algorithms to CVI processes in carbon/carbon composites. Acta Mater, 52, 299-305 http://dx.doi.org/10.1016/j.actamat.2003.09.020

Basheer, I. A., \& Hajmeer, M. (2000). Artificial neural networks: fundamentals, computing, design, and application. J Microbiol Methods, 43, 3-31.

Bhadeshia, H. K. D. H. (1999). Neural networks in materials science. ISIJ Int. 39, 966-979.

Brady, M. P., \& Tortorelli, P. F. (2004), Alloy design of intermetallics for protective scale formation and for use as precursors for complex ceramic phase surfaces Intermetallics. 12, 779-789 http://dx.doi.org/10.1016/j.intermet.2004.02.019

Chattopadhyay, P. P, Gannabattula, R. N. R., Pabi, S. K., \& Manna, I. (2001). Development of amorphous A165Cu35-xTix alloys by mechanical alloying. Scripta Materialia, 45, 1191-1196. http://dx.doi.org/10.1016/S1359-6462(01)01149-6

Datta, S., Pettersson, F., Ganguly, S., Saxén, H., \& Chakraborti, N. (2007). Designing high strength multi-phase steel for improved strength-ductility balance using Neural Networks and Multi-objective Genetic Algorithms. ISIJ Int. 47, 1193-2001

Fecht, H. J. (1992). High-energy planetary ball milling apparatus and method for the preparation of

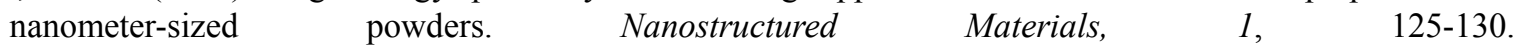
http://dx.doi.org/10.1016/0965-9773(92)90064-5

Gregg, S. J., \& Sing, K. S. W. (1982). Adsorption, Surface Area and Porosity. London: Harcourt Brace Jovanovich, 25-40.

Geyer, U., Johnson, W. L., Schneider, S., Qiu, Y., Tombrell, T. A., \& Macht, M. P. (1996). Small atom diffusion and breakdown of the Stokes-Einstein relation in the supercooled liquid state of the Zr46.7Ti8.3Cu7.5Ni10Be27.5 alloy. Appl. Phys. Lett., 69, 2492-2494.

Inoue, A. (2000). Stabilization of metallic supercooled liquid and bulk amorphous alloys. Acta Mater., 48, 279306. http://dx.doi.org/10.1016/S1359-6454(99)00300-6

Jang, J. S. R., Sun, C. T., \& Mizutani, E. (1997). Neuro-fuzzy and soft computing: A computational Approach to Learning and Machine Intelligence. New Jersey: Prentice-Hall, Inc.

Kiminami, C. S., Basim, N. D., Kaufman, M. J., Amateau, M. F., Eden, T. J., \& Galbraith, G. J. (2001). Challenges in the development of aluminum-based bulk amorphous alloys. Key Eng. Mater., 189, 503-508.

Kawamura, Y., Mano, H., \& Inoue, A. (2001). Nanocrystalline aluminum bulk alloys with a high strength of $1420 \mathrm{MPa}$ produced by the consolidation of amorphous powders. Scripta Mater., 44, 1599-1604. http://dx.doi.org/10.1016/S1359-6462(01)00781-3

Liu, R. S., Dong, K. J., Li, J. Y., Yu, A. B., \& Zou, R. P. ( 2005). Formation and description of nano-clusters formed during rapid solidification processes in liquid metals. Journal of Non-Crystalline Solids, 351, 612-617. http://dx.doi.org/10.1016/j.jnoncrysol.2005.01.038

Li, J. C., Zhao, Z. K., \& Jiang, Q. (2003). Mechanical properties of a high-strength A190Mn8Ce2 alloy. Adv. Eng. Mater, 5, 119 -122.

Lin, Y. C, Zhang, J., \& Zhong, J. (2008). Application of neural networks to predict the elevated temperature flow behavior of a low alloy steel. Computational Mater. Sci., 43, $752-758$ http://dx.doi.org/10.1016/j.commatsci.2008.01.039

Manaila, R., Macovei, D., Popescu, R., Devenyi, A., Jianu, A., \& Vasile, E. ( 2000). Nano-icosahedral Al-Mn-Ce phases: structure and local configurations. Mater. Sci. Eng. A., 294, 82-85. http://dx.doi.org/10.1016/S0921-5093(00)01203-X

Manna, I., Nandi, P., Bandyopadhyay, B., Ghoshray, K., \& Ghoshray, A. ( 2004). Microstructural and nuclear magnetic resonance studies of solid-state amorphization in Al-Ti-Si Composites prepared by mechanical 
alloying. Acta Mater., 52, 4133-4142. http://dx.doi.org/10.1016/j.actamat.2004.05.026

Manna, I., Nandi, P., \& Nambissan, P. M. G. (2004). Mechanism and kinetics of solid-state amorphization by mechanical alloying of Al65Cu35-xNbx. Philosophical Magazine A, 84, 3585-3598. http://dx.doi.org/10.1080/14786430412331283613

Manna, I., Chattopadhyay, P. P., Banhart, F., \& Fecht, H. J. (2004). Development of amorphous and nanocrystalline Al65Cu35-xZrx alloys by mechanical alloying. Mater. Sci. Engg A, 379, 360-365. http://dx.doi.org/10.1016/j.msea.2004.03.010

Masumoto, T. (1994). Recent progress in amorphous metallic materials in Japan. Mater. Sci. Eng. A, 179, 8-16. http://dx.doi.org/10.1016/0921-5093(94)90155-4

Maa, J., Zhu, S. G., Wuab, C. X., \& Zhang, M. L. (2009). Application of back-propagation neural network technique to high-energy planetary ball milling process for synthesizing nanocomposite $\mathrm{WC}-\mathrm{MgO}$ powders. Materials and Design, 30, 2867-2874. http://dx.doi.org/10.1016/j.matdes.2009.01.016

McBride, J., Malinov, S., \& Sha, W. (2004). Modelling tensile properties of gamma-based titanium aluminides using artificial neural network. Mater. Sci. and Eng. A., 384, 129-137 http://dx.doi.org/10.1016/j.msea.2004.05.072

Matlab Neural Network Toolbox ${ }^{\text {TM }} 6$ User's Guide:Howard Demuth, Mark Beale, Martin Hagan, 1992-2010 by The MathWorks, Inc.

Nygren, M., \& Shen, Z. J. (2003). On the preparation of bio-, nano- and structural ceramics and composites by spark plasma sintering. Solid State Sci., 5,125-131.

Peker, A, \& Johnson, W. L. (1993). A highly processable metallic glass: Zr42.2Ti13.8Cu12.5Ni10.0Be22.5 Applied Physics Letter, 63, 2342-2344.

Roy, D., Kumari, S., Mitra, R., \& Manna, I. (2007). Microstructure and mechanical properties of mechanically alloyed and spark plasma sintered amorphous-nanocrystalline A165Cu20Ti15 intermetallic matrix composite reinforced with $\mathrm{TiO} 2$ nanoparticles. Intermetallics, 15, 1595-1605. http://dx.doi.org/10.1016/j.intermet.2007.06.012

Roy, D., Chudoba, T., Witczak, Z., Lojkowski, W., Fecht, Hans-Jörg, Mitra, R., \& Manna, I. (2008). Structure and mechanical properties of Al65Cu20Ti15-based amorphous/nanocrystalline alloys prepared by high-pressure sintering. Mater. Sci. Eng. A., 497, 93-100. http://dx.doi.org/10.1016/j.msea.2008.07.059

Roy, D. (2008). PhD Thesis, IIT Kharagpur, India.

Suryanarayana, C. (2001). Mechanical Alloying and Milling Prog. Mater. Sci., 46, 1-184.

Schurack, F., Eckert, J., \& Schultz, L. ( 2000). Quasicrystalline Al-alloys with high strength and good ductility. Mater. Sci. Eng. A, 294, 164-167. http://dx.doi.org/10.1016/S0921-5093(00)01191-6

Sha, W, \& Edwards, K. L. (2007). The use of artificial neural networks in materials science based research. Mater Design, 28, 1747-52. http://dx.doi.org/10.1016/j.matdes.2007.02.009

Senkov, O. N., Senkova, S. V., Scott, J. M., \& Miracle, D. B. (2005). Compaction of amorphous aluminum alloy powder by direct extrusion and equal channel angular extrusion. Mater. Sci. Eng. A, 393, 12-21. http://dx.doi.org/10.1016/j.msea.2004.09.061

Witczak, Z. (1997). Acoustic emission investigations of the ductility of L12Al3Ti+Cr under high hydrostatic pressure. Mater. Sci. Eng. A, 239, 206-212. http://dx.doi.org/10.1016/S0921-5093(97)00583-2 